\title{
Novel CHOP activator LGH00168 induces necroptosis in A549 human lung cancer cells via ROS-mediated ER stress and NF-kB inhibition
}

\author{
Yi-ming MA ${ }^{1, \#}$, Yan-min PENG ${ }^{1, ~ \#, ~ Q i o n g-h u a ~ Z H U ~}{ }^{3, ~ \#, ~ A n-h u i ~ G A O ~}{ }^{1, ~ \#, ~ B o ~ C H A O ~}{ }^{2}$, Qiao-jun $\mathrm{HE}^{3}$, Jia $\mathrm{LI}^{1}$, You-hong $\mathrm{HU}^{1}$, \\ Yu-bo ZHOU ${ }^{1,2, *}$ \\ ${ }^{1}$ State Key Laboratory of Drug Research, Shanghai Institute of Materia Medica, Chinese Academy of Sciences, Shanghai 201203, \\ China; ${ }^{2}$ State Key Laboratory of Natural and Biomimetic Drugs, Peking University, Beijing 100871, China; ${ }^{3}$ Department of \\ Pharmacology and Toxicology, College of Pharmaceutical Sciences, Zhejiang University, Hangzhou 310058, China
}

Aim: $\mathrm{C} / \mathrm{EBP}$ homologous protein (CHOP) is a transcription factor that is activated at multiple levels during ER stress and plays an important role in ER stress-induced apoptosis. In this study we identified a novel CHOP activator, and further investigated its potential to be a therapeutic agent for human lung cancer.

Methods: HEK293-CHOP-luc reporter cells were used in high-throughput screening (HTS) to identify CHOP activators. The cytotoxicity against cancer cells in vitro was measured with MTT assay. The anticancer effects were further examined in A549 human nonsmall cell lung cancer xenograft mice. The mechanisms underlying CHOP activation were analyzed using luciferase assays, and the anticancer mechanisms were elucidated in A549 cells.

Results: From chemical libraries of 50000 compounds, LGH00168 was identified as a CHOP activator, which showed cytotoxic activities against a panel of 9 cancer cell lines with an average $\mathrm{IC}_{50}$ value of $3.26 \mu \mathrm{mol} / \mathrm{L}$. Moreover, administration of LGH00168 significantly suppressed tumor growth in A549 xenograft bearing mice. LGH00168 activated CHOP promoter via AARE1 and AP1 elements, increased DR5 expression, decreased Bcl-2 expression, and inhibited the NF-kB pathway. Treatment of A549 cells with LGH00168 (10 $\mu \mathrm{mol} / \mathrm{L})$ did not induce apoptosis, but lead to RIP1-dependent necroptosis, accompanied by cell swelling, plasma membrane rupture, lysosomal membrane permeabilization, MMP collapse and caspase 8 inhibition. Furthermore, LGH00168 (10 and $20 \mu \mathrm{mol} / \mathrm{L}$ ) dose-dependently induced mito-ROS production in A549 cells, which was reversed by the ROS scavenger N-acetyl-L-cysteine (NAC, $10 \mathrm{mmol} / \mathrm{L})$. Moreover, NAC significantly diminished LGH00168-induced CHOP activation, NF-kB inhibition and necroptosis in A549 cells.

Conclusion: LGH00168 is a CHOP activator that inhibits A549 cell growth in vitro and lung tumor growth in vivo.

Keywords: CHOP; LGH00168; ER stress; NF-kB; necroptosis; RIP1; ROS; non-small cell lung cancer A549 cells; cancer xenograft mice

Acta Pharmacologica Sinica (2016) 37: 1381-1390; doi: 10.1038/aps.2016.61; published online 6 Jun 2016

\section{Introduction}

Cancer is a leading cause of morbidity and mortality worldwide, with approximately 14 million new cases and 8.2 million cancer-related deaths worldwide in 2012. The lung was one of the most common sites of cancer diagnosed in 2012 (16.7\% of the total among men and $8.7 \%$ of the total among women $)^{[1]}$, with non-small cell lung cancer (NSCLC) accounting for 75\%

\footnotetext{
"These authors contributed equally to this work.

*To whom correspondence should be addressed.

E-mail ybzhou@simm.ac.cn

Received 2015-09-25 Accepted 2016-03-06
}

of all cases of lung cancer ${ }^{[2]}$; this statistic shows that NSCLC is an attractive disease for improved chemotherapy ${ }^{[3-6]}$.

The endoplasmic reticulum (ER) is a membrane-bound and structurally intricate organelle present in all eukaryotic cells; it is the primary site for the synthesis and folding of membrane and secretory proteins, and it also functions as storage for membrane lipids and internal calcium. Perturbations of ER homeostasis, a condition called ER stress, can be induced by homeostatic alterations that cause protein misfolding. These include redox status changes, nutrient deprivation, glycosylation changes, pathogen infection, and folding-defective protein expression ${ }^{[7]}$. ER stress activates the unfolded protein 
response (UPR), thereby re-establishing homeostasis in the ER, whereas extended ER stress activates apoptotic or necroptotic pathways in damaged cells ${ }^{[8-11]}$. Several UPR effectors, including X-Box Binding Protein $1(\mathrm{XBP} 1)^{[12]}$, Glucose-Regulated Protein, $78 \mathrm{kDa}(\mathrm{GRP} 78 / \mathrm{BiP})^{[13,14]}$ and CCAAT-enhancerbinding protein homologous protein $(\mathrm{CHOP})^{[15]}$, are commonly used as ER stress indicators. CHOP is a transcription factor that is activated at multiple levels during ER stress ${ }^{[16]}$. CHOP expression is kept very low in non-stressed cells but is strongly stimulated upon acute ER stress through IRE1-, PERK- and ATF6-dependent transcriptional induction. CHOP overexpression promotes apoptosis in several cell lines, while $\mathrm{CHOP}^{-/-}$cells are resistant to ER stress-induced apoptosis ${ }^{[17,18]}$. This finding suggests that CHOP plays an important role in ER stress-induced apoptosis. The downregulation of the antiapoptotic protein Bcl-2 and the activation of the pro-apoptotic proteins Bim, Puma, Bax and DR5 are considered to contribute to $\mathrm{CHOP}$-mediated apoptosis ${ }^{[17-19]}$. Moreover, the induction of caspase-independent necrosis by ER stress inducers can be blocked by the RIP1 inhibitor necrostatin-1 (Nec-1), indicating that ER stress can also induce necroptosis ${ }^{[8]}$.

Apoptosis and necrosis are two distinct cell death pathways $^{[20]}$. Apoptosis is highly regulated programmed cell death that is morphologically characterized by cytoplasmic shrinkage, chromatin condensation, phosphatidylserine externalization, DNA fragmentation, and the formation of apoptotic bodies without a loss of plasma membrane integrity ${ }^{[21]}$. By contrast, necrosis is viewed as unprogrammed cell death caused by external factors, such as trauma or infection. Necrosis is characterized by the swelling of cells, the early breakdown of plasma membranes, and the induction of inflammatory responses resulting from released cellular content ${ }^{[22]}$. Recently a new form of regulated necrosis, called necroptosis, has been recognized as an alternative form of programmed cell death ${ }^{[23]}$. Necroptosis is generally triggered by ligands of the death receptor family when caspase-dependent apoptotic pathways are inhibited ${ }^{[24]}$. Death receptors are members of the TNFR superfamily and are major mediators of cell death ${ }^{[25]}$. The activation of death receptors by their respective ligands recruits and activates caspase 8 at the death-inducing signaling complex (DISC) and triggers apoptosis in the absence of the NF-KB survival pathway ${ }^{[26]}$. Under caspase 8 inhibition, necroptosis can be stimulated via an RIP1 kinase and the activation of RIP3 by an RIP1 kinase and MLKL ${ }^{[27-30]}$. Inhibition of an RIP1 kinase by a specific RIP1 kinase inhibitor Nec-1 blocks the initiation of necroptosis ${ }^{[3]}$. Alternatively, reactive oxygen species (ROS) also play important roles in necroptosis. Antioxidant treatment can reduce ROS levels and also inhibit cell death in some but not all cell types ${ }^{[32,33]}$, suggesting that ROS is an executioner of necroptosis in a cell type-dependent manner. Here, we stably introduced a CHOP luciferase reporter into a cell line as a tool to identify ER stress inducers for lung cancer therapy in humans. Using high-throughput screening (HTS), we evaluated one series of analogs for their CHOP-inducing activities; of these analogs, the active compound LGH00168 was further examined as a CHOP activator. The NSCLC cell line A549 is a well-studied lung adenocarcinoma cell line that has been used in xenograft models, including orthotopic xenograft models, of NSCLC to study primary tumor growth and metastasis ${ }^{[34]}$. Further investigation of the anti-cancer mechanism was performed in A549 human lung cancer cells. LGH00168 inhibited A549 cell growth in vitro and A549 lung tumor growth in vivo. Mechanistic experiments demonstrated that LGH00168 induces necroptosis via ROS production.

\section{Materials and methods \\ Cell culture}

All of the cell lines mentioned in this paper were obtained from the Cell Bank (Chinese Academy of Sciences, Shanghai, China). The HeLa human cervical cancer cell line and the MCF-7 human breast cancer cell line were cultured in DMEM (high glucose) containing 10\% FBS. The MDA-MB-231 human breast cancer cell line, COLO 205 human colon cancer cell line and NCI-H1299 human lung cancer cell line were cultured in RPMI-1640 medium containing 10\% FBS. The HCT116 human colon cancer cell line and SK-OV-3 human ovarian cancer cell line were cultured in McCoy's 5A modified medium containing 10\% FBS. The A549 human lung cancer cell line was cultured in Ham's F12 medium containing 10\% FBS. These cells were maintained in a humidified atmosphere of $5 \% \mathrm{CO}_{2}$ and $95 \%$ air at $37^{\circ} \mathrm{C}$.

\section{Reagents}

LGH00168 was obtained from Specs (Delft, The Netherlands). DMEM media (high glucose; Cat \#11995-065), RPMI-1640 media (Cat \#31800022), MEM media (Cat \#11575032), Ham's F-12 media (Cat \#21700-075), Hoechst 33342 (Cat \#H3570), JC-1 Dye (Cat \#T-3168), and MitoSOX ${ }^{\circledast}$ Red mitochondrial superoxide indicator (Cat \#M36008) were obtained from Life Technologies (Grand Island, NY, USA). Hyclone FBS (Cat \#SH30071.01) and ECL Western blotting detection reagents (Cat \#RPN2108) were purchased from GE Healthcare Life Sciences (Logan, UT, USA). Penicillin/streptomycin (Cat \#15140122) was purchased from the Invitrogen Corporation (Carlsbad, CA, USA). Paclitaxel (Cat \#T7402), methylthiazolyldiphenyl-tetrazolium bromide (Cat \#M2003), sulforhodamine B (Cat \#S1402), N-Acetyl-L-Cysteine (Cat \#A7250), propidium iodide (Cat \#P4170), Acridine Orange hemi (zinc chloride) salt (Cat \#A6014), and McCoy's 5A modified media (Cat \#M4892) were purchased from Sigma-Aldrich (St Louis, MO, USA). A CellTiter-Glo ${ }^{\circledast}$ luminescent cell viability assay kit (Cat \#G7573) and Steady-Glo ${ }^{\circledast}$ Luciferase Assay System (Cat \#E2550) were purchased from Promega (Madison, WI, USA). An Annexin V-FITC/PI double staining kit (Cat \#KGA108) was purchased from Kaiji Bio Co (Nanjing, China).

\section{MTT cytotoxicity assay}

An MTT viability assay was used to evaluate the anti-proliferative effects of LGH00168 on different cancer cell lines ${ }^{[35]}$. Briefly, cells were seeded into 96-well plates and cultured at $37^{\circ} \mathrm{C}$. After $24 \mathrm{~h}$, compounds at concentrations ranging from $0.63 \mu \mathrm{mol} / \mathrm{L}$ to $20 \mu \mathrm{mol} / \mathrm{L}$ were added at a dilution of 
1:2. Three days later, MTT was added. After $3 \mathrm{~h}$ of incubation, the medium was discarded, DMSO was added, and the optical density was determined at 550/690 nm using a VersaMax microplate reader (Molecular Devices, Sunnyvale, CA, USA). Experiments were performed in triplicate. $\mathrm{IC}_{50}$ values were derived from a nonlinear regression model (curvefit) based on a sigmoidal dose response curve (variable slope) and computed using GraphPad Prism version 5.02 (GraphPad Software Inc, La Jolla, CA, USA). Data were expressed as the mean \pm SEM.

Anti-tumoral effect of LGH00168 in lung carcinoma-bearing mice Tumor xenografts were established by the injection of A549 cells $\left(5 \times 10^{6}\right.$ cells/animal, $s c$ into the armpit of athymic mice) into 4- to 5-week-old BALB/c female athymic mice (National Rodent Laboratory Animal Resource, Shanghai, China). Tumor volume (cubic millimeters) was measured with calipers and calculated by the following formula: volume $=\mathrm{W}^{2} \times \mathrm{L} / 2$, where $\mathrm{W}$ is the short diameter, and $\mathrm{L}$ is the long diameter. When tumors reached a mean group size of approximately $110 \mathrm{~mm}^{3}$, the mice were randomized into treatment groups (5 mice per group), and treatment was commenced. The mice were administered with LGH00168 (5, 10, and $20 \mathrm{mg} / \mathrm{kg}$, im), a vehicle (tea tree oil), or the positive control Paclitaxel (10 $\mathrm{mg} / \mathrm{kg}$ ) once every $2 \mathrm{~d}$. The tumor volumes were recorded every $3 \mathrm{~d}$. Animal care was in accordance with institutional guidelines.

\section{Propidium iodide/Hoechst 33342 (PI/HO) double staining}

Plasma membrane permeability (PMP) and nuclear morphology were evaluated using PI/HO double staining as described previously ${ }^{[36]}$ with modifications as follows: A549 cells were cultured on glass coverslips and incubated with LGH00168 for $4 \mathrm{~h}$. Next, the cells were stained with $40 \mathrm{mg} / \mathrm{L}$ of PI and $20 \mathrm{mg} / \mathrm{L}$ of Hoechst 33342 in $1 \times$ PBS for 15 min in the dark. After washing twice with $1 \times$ PBS, the slides were mounted, sealed and observed under an Olympus BX51 fluorescence microscope (Tokyo, Japan). Images were captured with an Olympus DP72 digital camera (Tokyo, Japan) and analyzed using Adobe Photoshop CS4 software (San Jose, CA, USA).

\section{Annexin V/PI analysis}

The quantitative assessment of cell death was determined using an Annexin V/PI double staining kit according to the manufacturer's instructions. Briefly, the cells were treated with LGH00168 for $4 \mathrm{~h}$. Next, $5 \times 10^{5}$ cells were collected, washed twice with cold $1 \times$ PBS, and stained with Annexin V and PI for $15 \mathrm{~min}$ at room temperature in the dark. Finally, the percentages of necrotic cells were measured using a BD FACSCalibur Flow Cytometer (BD Inc, San Jose, CA, USA) and analyzed with FCS Express V3 software (De Novo Software, Glendale, CA, USA).

Determination of lysosomal membrane permeabilization (LMP) using acridine orange/Hoechst33342 (AO/HO) staining

The metachromatic fluorophore $\mathrm{AO}$ is retained in its charged form $\left(\mathrm{AOH}^{+}\right)$by proton trapping within the acidic vacuolar compartment. When normal cells are excited by blue light, highly concentrated lysosomal AO emits an intense red granular fluorescence, and the nuclei and cytosol show weak diffuse green fluorescence. LMP results in reduced red fluorescence and bright green cytoplasmic and nuclear fluorescence. LMP induction by LGH00168 was observed using AO/HO double staining ${ }^{[37]}$. Cells were treated with LGH00168 for $4 \mathrm{~h}$ and then were incubated with $5 \mathrm{mg} / \mathrm{L}$ of $\mathrm{AO}$ for $10 \mathrm{~min}$ in the dark. Images were captured with an Olympus DP72 digital camera (Tokyo, Japan) and analyzed in Adobe Photoshop CS4 software (San Jose, CA, USA).

\section{Caspase 8 activity evaluation}

Caspase 8 activity was evaluated using the Caspase-Glo 8 assay system (Promega, Madison, WI, USA) according to the manufacturer's instructions. Briefly, the cells were treated as described with LGH00168 before the addition of 1/2 volume of the assay reagent. The lysates were then incubated at room temperature for $1 \mathrm{~h}$ before luminescence was measured on an EnVision Multilabel Plate Reader (Perkin Elmer, Waltham, MA, USA).

\section{Quantitative polymerase chain reaction ( $\mathrm{QPCR}$ ) detection of CHOP, Bcl-2, and DR5}

qPCR was utilized to detect the CHOP, Bcl-2, and DR5 mRNA levels. Briefly, cells were treated with $10 \mu \mathrm{mol} / \mathrm{L}$ of LGH00168 for $0,5,24$, and $48 \mathrm{~h}$. Next, the total RNA was extracted using a TRIzol reagent (Invitrogen, Carlsbad, CA, USA) according to the manufacturer's instructions. GAPDH was used as an internal control. Complementary DNA generated by M-MLV Reverse Transcriptase (Promega, Madison, WI, USA) was analyzed by qPCR using SYBR ${ }^{\circledR}$ Premix Ex Taq II (TaKaRa, Dalian, China). The sequences of the primers were as follows: human CHOP forward 5'-CTGCAAGAGGTCCTGTCTTCA-3' and reverse 5'-TGTTTCCGTTTCCTGGTTCTC-3'; human Bcl-2 forward 5'-ATGTGTGTGGAGAGCGTCAA-3' and reverse 5'-ACAGTTCCACAAAGGCATCC-3'; human DR5 forward 5'-CACTCACTGGAATGACCTCCT-3' and reverse 5'-CACTGTGCTTTGTACCTGATTCT-3'. All of the reactions were performed in triplicate, and the cycle threshold (CT) value in each reaction well was recorded. The relative quantification of CHOP, Bcl-2, and DR5 mRNA expression was calculated using the $2^{-\triangle \Delta C T}$ method.

\section{Western blot analysis}

Cells were treated with LGH00168 and then lysed with a cell lysis buffer $(1 \% \mathrm{NP}-40,150 \mathrm{mmol} / \mathrm{L}$ of $\mathrm{NaCl}, 20 \mathrm{mmol} / \mathrm{L}$ of Tris- $\mathrm{HCl}, 1 \mathrm{mmol} / \mathrm{L}$ of EDTA, $1 \mathrm{mmol} / \mathrm{L}$ of EGTA and complete protease inhibitor cocktail). The lysates were fractionated by SDS-PAGE, transferred to Hybond-C nitrocellulose membranes (GE Life Sciences, Pittsburgh, PA, USA) and immunoblotted as described previously ${ }^{[24]}$. Immunoreactive bands were detected using ECL Western blotting detection reagents (Cat \#RPN2108, GE Life Sciences, Pittsburgh, PA, USA). 


\section{Luciferase assay}

HEK293-ERSE-luc, HEK293-AARE1-luc, HEK293-AARE2-luc, HEK293-AP1-luc, HEK293-NF-kB-luc, or HEK293-CHOP-luc reporter cells were seeded into 96-well plates and cultured at $37^{\circ} \mathrm{C}$. After $24 \mathrm{~h}$, different doses of drugs were added. After $24 \mathrm{~h}$ of treatment, luciferase activity was determined using the Promega Steady-Glo luciferase assay system according to the manufacturer's instructions. The luminescent signal was recorded using the EnVision Multilabel Plate Reader (Perkin Elmer, Waltham, MA, USA). All of the luciferase assay experiments were repeated at least three times.

\section{Measurement of the mitochondrial ROS (mito-ROS)}

The mito-ROS level was examined by a MitoSOX Red mitochondrial superoxide indicator (Cat \#M36008, Life technologies, Grand Island, NY, USA) according to the manufacturer's instructions. Briefly, cells were treated with LGH00168 for $1 \mathrm{~h}$, collected by trypsin treatment, washed twice with ice-cold $1 \times$ PBS, and then incubated with $5 \mu \mathrm{mol} / \mathrm{L}$ of MitoSOX for $20 \mathrm{~min}$ in the dark. The mito-ROS level was measured using a BD FACSCalibur Flow Cytometer and analyzed with FCS Express V3 software (De Novo Software, Glendale, CA, USA).

\section{Measurement of the mitochondrial membrane potential $(\Delta \psi \mathrm{m})$}

The $\Delta \psi \mathrm{m}$ level was measured using a JC-1 dye (Cat \#T-3168, Life Technologies, Grand Island, NY, USA) according to a previous report with modifications ${ }^{[38]}$. Briefly, cells were seeded into black-bottomed 96-well optical plates (Greiner Bio-One, Dusseldorf, Germany). After 24 h, LGH00168 was added, and the cells were incubated at $37^{\circ} \mathrm{C}$ for $1 \mathrm{~h}$. JC-1 at a final concentration of $10 \mathrm{mg} / \mathrm{L}$ was then added. The plates were incubated for another $20 \mathrm{~min}$ at $37^{\circ} \mathrm{C}$, and each well was washed three times with a Krebs-Ringer phosphate HEPES buffer. Fluorescence was measured in a Flexstation II plate reader (Molecular Device, Union City, CA, USA) first at excitation and emission wavelengths of (Ex/Em) $530 \mathrm{~nm} / 580 \mathrm{~nm}$ ("red") and then at Ex/Em 485 nm/530 nm ("green"). The ratio of red to green reflects $\Delta \psi m$. The results were analyzed using GraphPad Prism version 5.02 (GraphPad Software Inc, La Jolla, CA, USA).

\section{Measurement of the cellular ATP level}

The cellular ATP level was detected using a CellTiter-Glo assay (Cat \#G7573; Promega, Madison, WI, USA). Briefly, cells (5000 cells per well) were seeded into white-bottomed 96-well plates and cultured at $37^{\circ} \mathrm{C}$. After $24 \mathrm{~h}$, the cells were treated with LGH00168 for $4 \mathrm{~h}$. Next, the plates were equilibrated at room temperature for $30 \mathrm{~min}$, a CellTiter-Glo reagent was added, and the plates were shaken with an orbital shaker for $2 \mathrm{~min}$. After incubation at room temperature for $10 \mathrm{~min}$, the luminescent signal was recorded using the EnVision Multilabel Plate Reader (Perkin Elmer, Waltham, MA, USA).

\section{Sulforhodamine B (SRB) assay}

The SRB assay was used to evaluate the effect of NAC (N-Acetyl-L-Cysteine) on LGH00168-induced cell death ${ }^{[7]}$. Briefly, cells were seeded into 96-well plates and cultured at $37^{\circ} \mathrm{C}$. After 24 h, LGH00168 with final concentrations ranging from $20 \mu \mathrm{mol} / \mathrm{L}$ to $2.5 \mu \mathrm{mol} / \mathrm{L}$ at a dilution ratio of $1: 2$ with or without NAC (final concentration: $10 \mathrm{mmol} / \mathrm{L}$ ) was added, and the cells were further incubated for $72 \mathrm{~h}$. Next, the cells were fixed with $3.3 \%(w / v)$ trichloroacetic acid for $1 \mathrm{~h}$ at $4{ }^{\circ} \mathrm{C}$ and stained with $0.4 \%$ SRB dissolved in $1 \%(v / v)$ acetic acid for $30 \mathrm{~min}$. The unbound dye was removed by four washes with $1 \%$ acetic acid, and the protein-bound dye was extracted with $10 \mathrm{mmol} / \mathrm{L}$ of an unbuffered Tris base ( $\mathrm{pH}$ 10.5) for 5 min. The optical density was determined at $510 \mathrm{~nm}$ using a VersaMax Microplate Reader (Molecular Devices, Sunnyvale, CA, USA). Experiments were performed in triplicate. $\mathrm{IC}_{50}$ values were derived from a nonlinear regression model (curvefit) based on a sigmoidal dose response curve (variable slope) and computed using GraphPad Prism version 5.02 (GraphPad Software Inc, La Jolla, CA, USA). Data were expressed as the mean \pm SEM.

\section{NAC treatment}

To evaluate the role of ROS in the anticancer activity of LGH00168 against A549 lung cancer cells, NAC (final concentration: $10 \mathrm{mmol} / \mathrm{L}$ ) was used as ROS scavenger. mRNA levels of CHOP, protein levels of p-p65, p65, IkBa, and $\beta$-actin, levels of LMP, MMP, and cellular viability were evaluated in LGH00168-treated cells with or without NAC.

\section{Statistical analysis}

The statistical analyses were performed by paired two-tailed Student's $t$-tests (GraphPad Prism version 5.02, GraphPad Software Inc, La Jolla, CA, USA). A level of $P<0.05$ was considered statistically significant. The data are presented as the mean \pm SEM.

\section{Results}

LGH00168 was identified as a CHOP activator that inhibited A549 cell growth in vitro and lung tumor growth in vivo

A high-throughput screening (HTS) assay was utilized to identify CHOP activators from 50000 compounds from the chemical libraries of the Chinese National Center for Drug Screening (data not shown). LGH00168 was identified from among its analogs (Figure 1A) as a CHOP activator (Figure 1B) with good cytotoxic activity in vitro (Figure $1 \mathrm{C}$ ) and in vivo (Figure 1D, 1E). LGH00168 showed good cytotoxic effects against nine cancer cell lines that were derived from six different tissues, with an average $\mathrm{IC}_{50}$ value of $3.26 \mu \mathrm{mol} / \mathrm{L}$ in vitro. Moreover, LGH00168 effectively inhibited the growth of A549 tumor xenografts in vivo compared with the control group.

\section{LGH00168 induced CHOP activation and NF-KB inhibition}

CHOP promoter-luciferase reporter assays demonstrated the activation of AARE1 and AP1 elements of the CHOP promoter by LGH00168 treatment (Figure 2A). qPCR results indicated increased DR5 expression and decreased Bcl-2 expression of two CHOP downstream targets in a time-dependent manner (Figure 2B). Moreover, a luciferase assay and Western blot 
A<smiles>CSc1nc(Cl)cc(-n2ncc(Cl)c(Cl)c2=O)n1</smiles>

LGH00166<smiles>COc1cc(Cl)nc(-n2ncc(Cl)c(Cl)c2=O)n1</smiles>

LGH00167<smiles>COc1cc(-n2ncc(Cl)c(Cl)c2=O)ncn1</smiles>

LGH00168<smiles>Cc1nc(Oc2ccccc2)cc(-n2ncc(Cl)c(Cl)c2=O)n1</smiles>

LGH00169<smiles>COc1cc(OC)nc(-n2ncc(Cl)c(Cl)c2=O)n1</smiles>

LGH00170

C

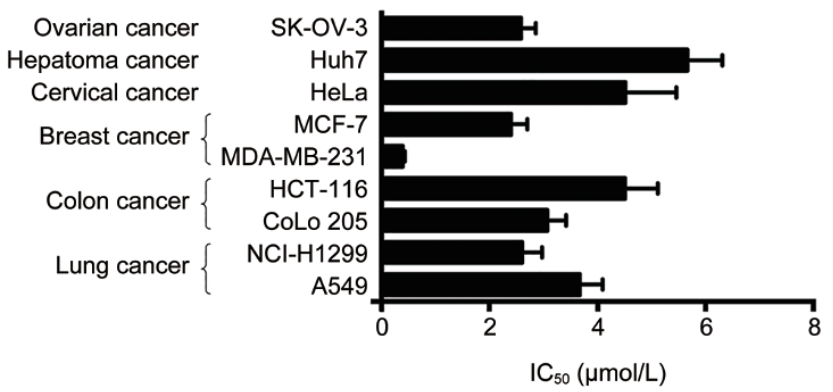

B

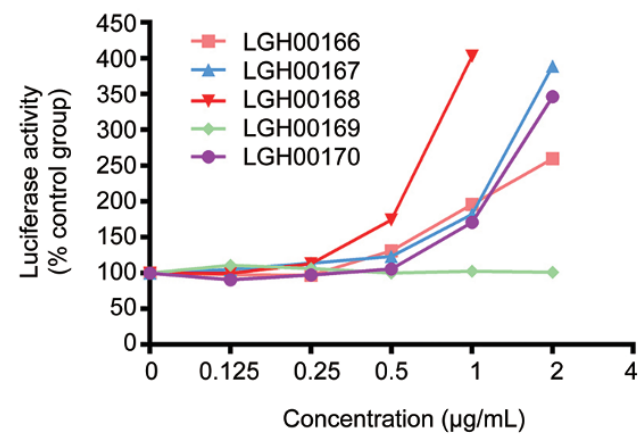

D

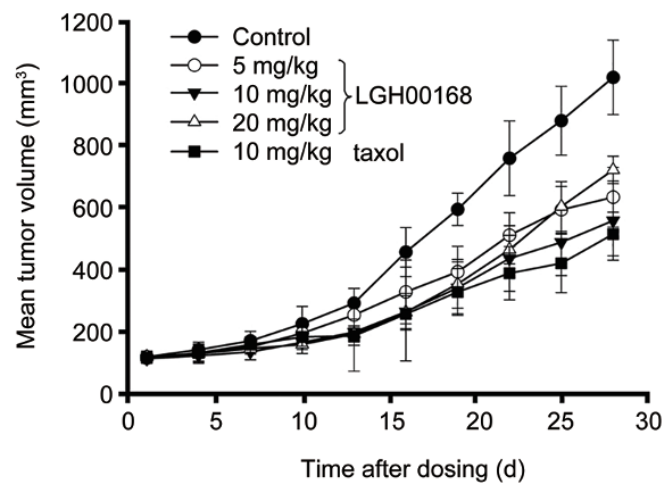

E

${ }^{\times x} p<0.01$ vs control.

\begin{tabular}{|c|c|c|c|c|c|c|c|c|c|}
\hline \multirow{2}{*}{ Group } & \multicolumn{2}{|c|}{$n$} & \multicolumn{2}{|c|}{ Body weight (g) } & \multicolumn{2}{|c|}{ Tumor size $\left(\mathrm{mm}^{3}\right)$} & \multirow{2}{*}{$\begin{array}{c}\text { Tumor } \\
\text { weight }(\mathrm{g})\end{array}$} & \multirow{2}{*}{$\begin{array}{r}\text { Inhibition } \\
\text { rate (\%) }\end{array}$} & \multirow[t]{2}{*}{$\mathrm{T} / \mathrm{C}(\%)$} \\
\hline & Start & End & Start & End & Start & End & & & \\
\hline Control & 5 & 5 & $20.78 \pm 0.85$ & $23.46 \pm 1.59$ & $118.90 \pm 18.20$ & $1018.95 \pm 119.77$ & $0.89 \pm 0.14$ & & \\
\hline LGH00168 (10 mg/kg) & 5 & 5 & $21.72 \pm 1.25$ & $21.48 \pm 1.20$ & $113.29 \pm 15.12$ & $557.62 \pm 127.16^{\star \star}$ & $0.57 \pm 0.15^{\star *}$ & 36.1 & 54.7 \\
\hline Taxol (10 mg/kg) & 4 & 4 & $21.32 \pm 0.63$ & $22.08 \pm 1.94$ & $116.84 \pm 15.91$ & $514.44 \pm 70.24^{\star *}$ & $0.50 \pm 0.11^{* *}$ & 44 & 50.4 \\
\hline
\end{tabular}

Figure 1. The CHOP activator LGH00168 inhibited the growth of A549 cells in vitro and lung tumor growth in vivo. (A) The chemical structure of LGH00168 analogs. (B) The induction of CHOP luciferase activities by LGH00168 analogs in HEK293 cells. (C) The anti-proliferative effects of LGH00168 on nine cancer cell lines derived from six different organs. (D) LGH00168 inhibited the growth of A549 tumor xenografts in nude mice. (E) LGH00168 inhibited tumor growth on A549 xenograft bearing mice.

data indicated the inhibitory effect of LGH00168 on the NF-кB pathway (Figure 2C and 2D).

\section{LGH00168 induced RIP1-dependent necroptosis}

The mechanism of LGH00168-induced cell death was investigated by morphological observation, $\mathrm{PI} / \mathrm{HO}$ double staining, and an Annexin V/PI assay. LGH00168 induced morphological changes and an increase in PI staining, which is a sign of plasma membrane rupture (Figure 3A). Moreover, an Annexin V/PI assay examination indicated that cell death was due to necrosis without apoptotic induction (Figure 3B). Additionally, the correspondent FSC signal decreased (Figure 3C), demonstrating that LGH00168-treated cells were dying.
Moreover, severe LMP and MMP collapse were induced after $4 \mathrm{~h}$ of treatment (Figure 3D and 3E), and caspase 8 activity was inhibited (Figure 3F). PI staining and a cell viability assay were utilized to evaluate whether LGH00168-induced necrosis can be reversed by the RIP1 inhibitor Nec-1. As shown in Figure $3 \mathrm{G}$ and $3 \mathrm{H}, \mathrm{Nec}-1$ partially reversed PI staining and cell death, indicating that LGH00168 induced RIP1-dependent necroptosis.

\section{LGH00168 induced mito-ROS production}

Mitochondria are reported as the main site of ROS generation. Additionally, superoxide $\left(\mathrm{O}_{2}{ }^{-{ }^{-}}\right)$is the primary mitochondrial ROS. We next examined whether $\mathrm{O}_{2}{ }^{--}$was generated in mito- 

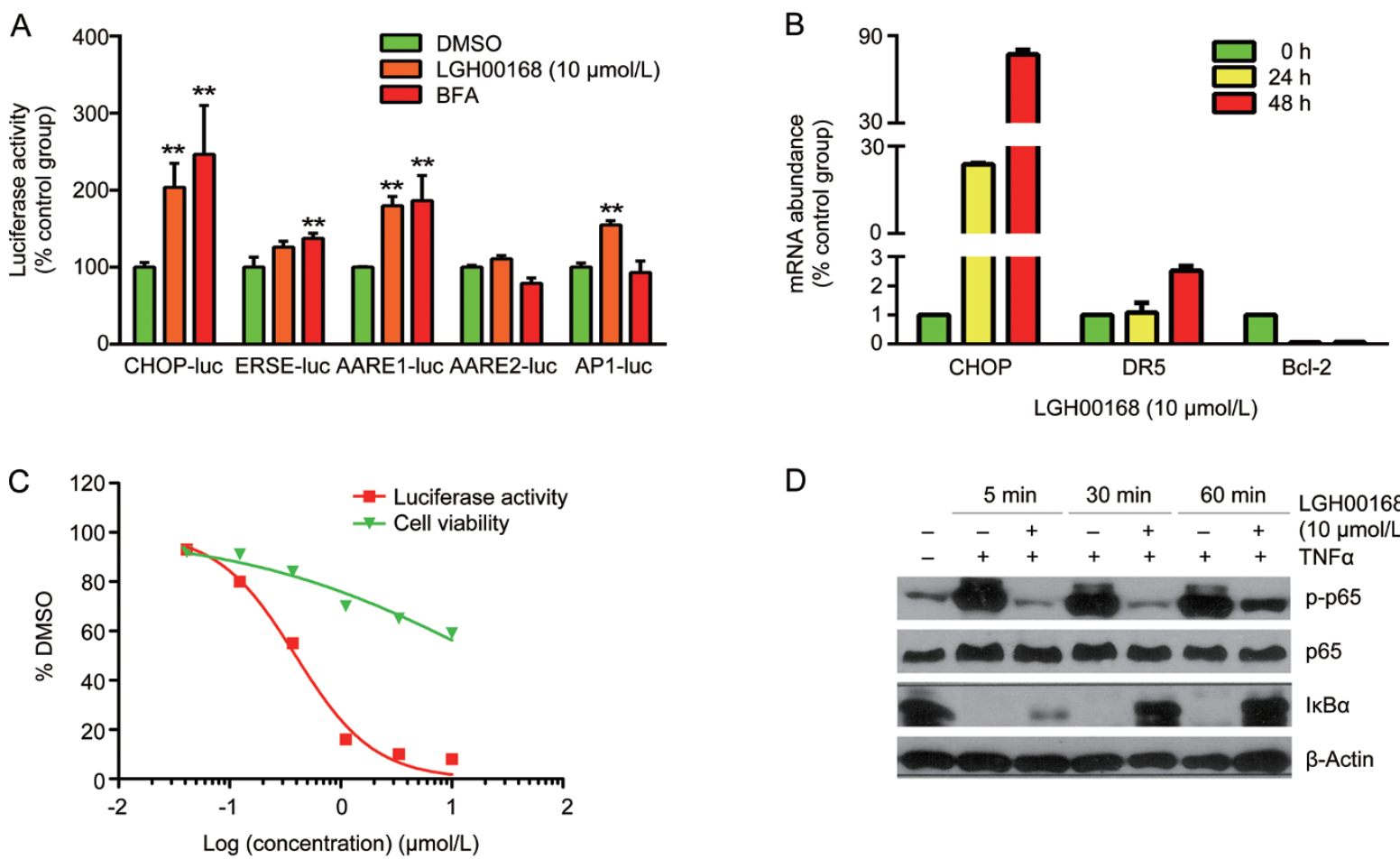

D

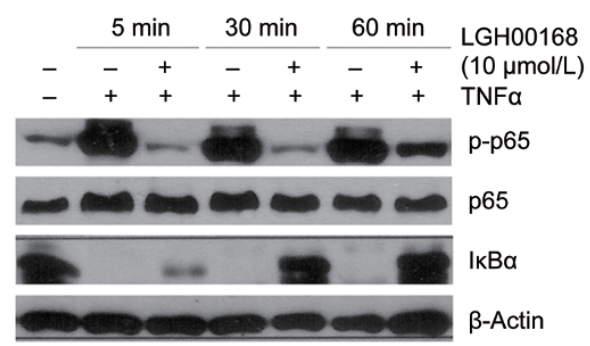

Figure 2. LGH00168 activated CHOP and inhibited the NF-KB pathway. (A) The luciferase assay indicated that CHOP was activated via the AARE1 and AP1 elements in HEK293 cells. ${ }^{* *} P<0.01$ vs DMSO group. (B) qPCR indicated that LGH00168 activated CHOP and DR5 in a time-dependent manner and inhibited Bcl-2. (C) The luciferase assay indicated the inhibitory effect of LGH00168 on NF-KB activity in HEK293 cells. (D) The Western blot assay indicated the inhibition of p-p65 and the accumulation of IKB $\alpha$ in LGH00168-treated cells.

chondria using the MitoSOX Red mitochondrial superoxide indicator, which only detects $\mathrm{O}_{2}{ }^{--}$generated in mitochondria. LGH00168 induced mito-ROS generation in a dose-dependent manner (Figure 4A), which was effectively reversed by the ROS scavenger NAC (Figure 4B).

The ROS scavenger NAC blocked LGH00168-induced CHOP activation, NF-KB inhibition, and necroptosis

NAC effectively blocked LGH00168-induced CHOP activation, NF-KB inhibition, LMP, and MMP collapse (Figure 5A-5D), indicating that these effects were dependent on ROS generation. Moreover, NAC completely blocked LGH00168-induced cell death (Figure 5E), showing that necroptotic cell death was dependent on ROS production.

\section{Discussion}

It has long been accepted that cell death can be classified into two types: apoptosis and necrosis ${ }^{[39]}$. The activation of necrotic events was considered, until recently, to be promoted by extensive cellular trauma, whereas apoptosis was considered to be driven by a genetically controlled cascade of events initiated by minor insults or extracellular signals ${ }^{[1,12]}$. Recent work has suggested that anti-cancer treatments also trigger other, non-apoptotic, cell death modalities (autophagy, mitotic catastrophe and necrosis) $)^{[40-43]}$. Additionally, some studies have found that necrosis induction enhances the anti-cancer efficacy for some chemo-resistant tumors ${ }^{[44-46]}$.

Here, LGH00168 was identified as a novel CHOP activator that effectively inhibited the in vitro growth of nine cancer cell lines derived from six different tissues and that inhibited lung tumor growth in vivo. As previously reported, cells undergoing apoptosis exhibit cardinal features such as changes in cellular and nuclear morphology, a non-random phosphatidylserine inversion on the plasma membrane, and the formation of apoptotic bodies. Additionally, cells undergoing necrosis will change morphologically, showing swelling with a rupture of the plasma membrane ${ }^{[20]}$. In this study, cells with typical apoptotic nuclei and cells in the early apoptotic stage were not observed; however, rupture of the plasma membrane was induced, suggesting that LGH00168 induces necrosis not apoptosis.

Necrosis is the consequence of extensive crosstalk between several biochemical and molecular events. Currently, there is no single well-described signaling cascade that defines necrotic cell death ${ }^{[19]}$. As previously reported, necrosis is the result of the interplay between several signaling cascades ${ }^{[47]}$, and it is thought to be regulated ${ }^{[48]}$. There are several important mediators involved in the propagation and execution of necrotic cell death, including ER stress induction, NF-kB inhibition, ROS, proteases, and ceramide ${ }^{[47]}$. Here, we found that LGH00168 induced necrotic cell death accompanied by ER stress induction, NF-kB inhibition, mito-ROS generation, severe LMP, and 
A

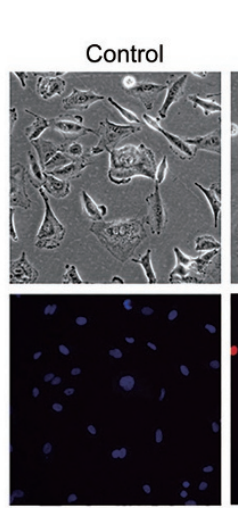

0

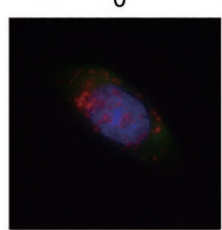

10

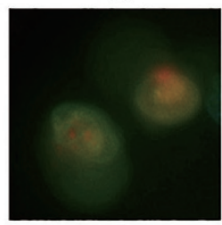

G
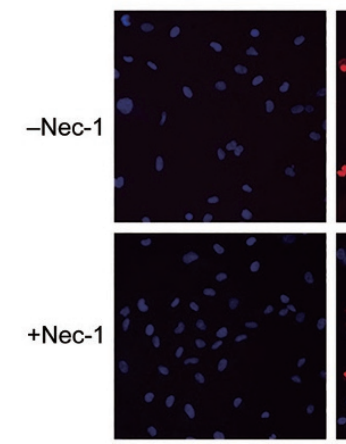

LGH00168

(10 $\mu \mathrm{mol} / \mathrm{L})$
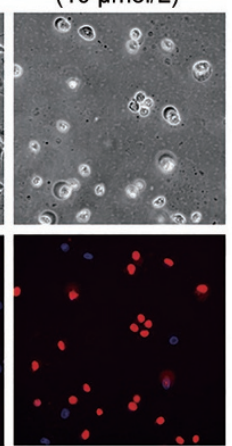

5

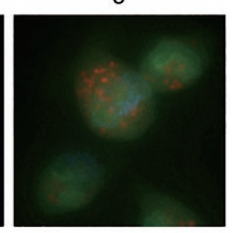

$20(\mu \mathrm{mol} / \mathrm{L})$

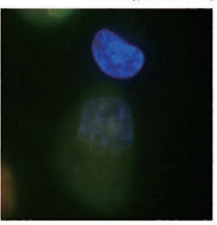

LGH00168 $(10 \mu \mathrm{mol} / \mathrm{L})$
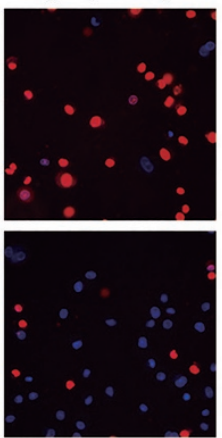

B

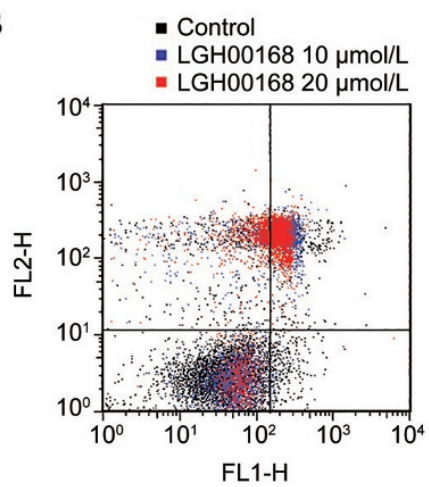

E

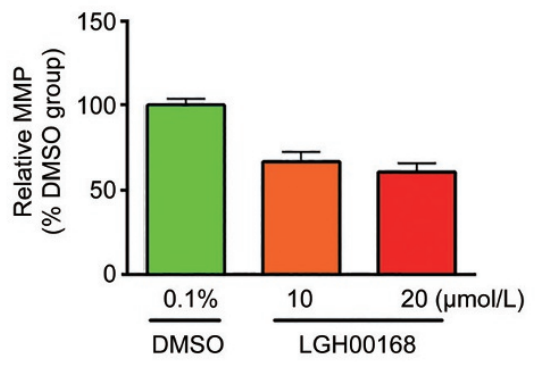

$\mathrm{H}$

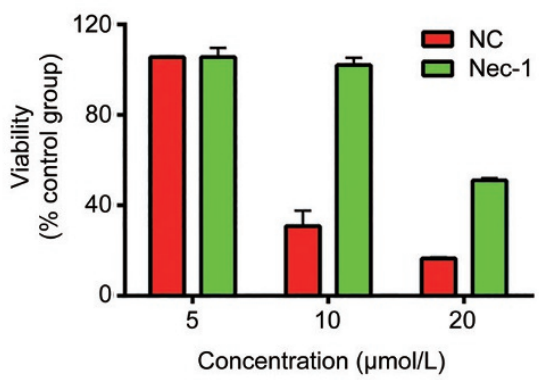

C

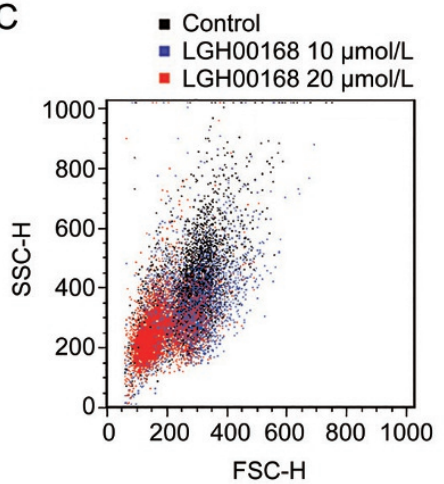

$\mathrm{F}$

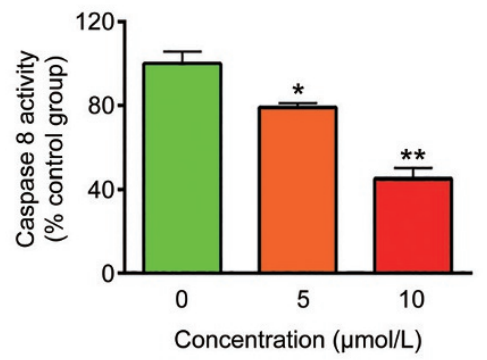

Figure 3. LGH00168 induced necroptosis in A549 cells. (A) Pl/HO staining indicated the induction of cellular swelling and plasma membrane rupture. (B) The Annexin V/PI assay indicated the induction of necrosis. (C) The SSC/FSC parameters showed cell death of LGH00168-treated cells. (D) AO/ EB staining indicated the induction of severe LMP. (E) JC-1 staining indicated the collapse of MMP in LGH00168-treated cells. (F) A caspase 8 activity assay indicated the inhibition of caspase 8 activity. (G) The RIP1 inhibitor Nec-1 partially reversed LGH00168-induced PMP. (H) The RIP1 inhibitor Nec-1 partially reversed LGH00168-induced necroptosis. ${ }^{*} P<0.05,{ }^{* *} P<0.01$.

the loss of $\Delta \psi \mathrm{m}$, which might be the mediators of LGH00168induced necrosis. As previously reported, an RIP1 kinase was found to initiate necrosome formation and trigger necroptosis, and we further utilized an RIP1 inhibitor, Nec-1, to evaluate the role of RIP1 in LGH00168-induced necrosis. Nec-1 effectively reversed LMP and necrotic cell death, indicating that LGH00168 induced RIP1-dependent necroptosis.

Mitochondria are the organelles that are central to many fundamental cellular processes, such as energy generation, and are an important source of ROS within most mammalian cells $^{[49]}$. We next examined whether LGH00168 induced the generation of ROS in mitochondria. Here, LGH00168 induced mito-ROS generation. The ROS scavenger NAC effectively eliminated excessive ROS and reversed the loss of MMP, the induction of LMP and necroptotic cell death, indicating that necroptosis was mainly induced through the production of ROS.

Necrosis is an irreversible inflammatory form of cell death, and it is also known that therapy-induced necrotic cell death initiates an immune response to tumor cells. However, whether the inflammation is associated with necrosis remains unclear, but therapeutics that target the regulators of 
A

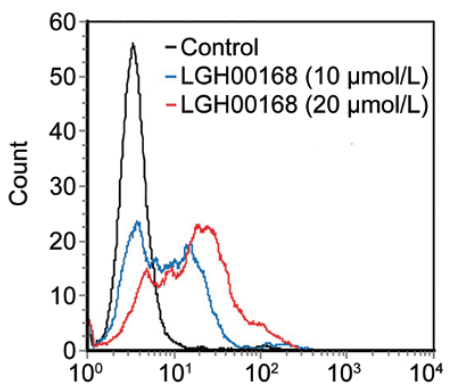

B

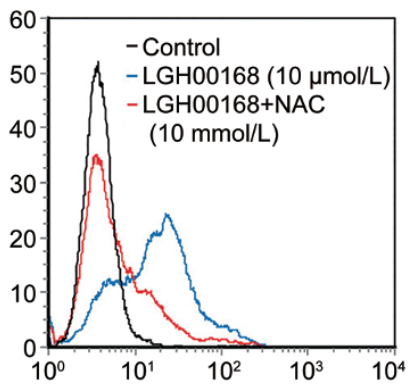

Figure 4. LGH00168 induced mito-ROS production in A549 cells. (A) LGH00168 induced mito-ROS production in a dose-dependent manner. (B) The ROS scavenger NAC (10 mmol/L) effectively blocked LGH00168induced mito-ROS production.

necrotic cell death are already in early-phase clinical trials ${ }^{[43]}$. It has been reported that a cell can initiate its own demise by necrosis, which initiates both inflammatory and/or repara-

A

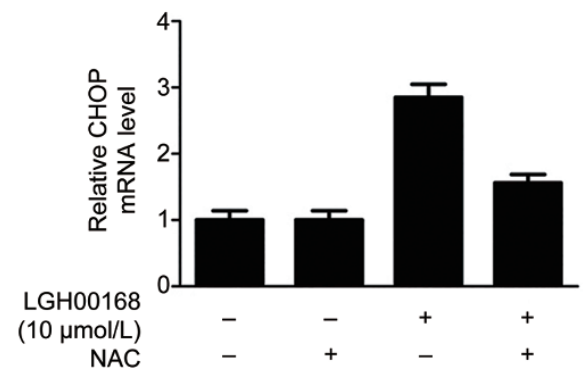

C LGH00168 $(10 \mu \mathrm{mol} / \mathrm{L})$

NAC
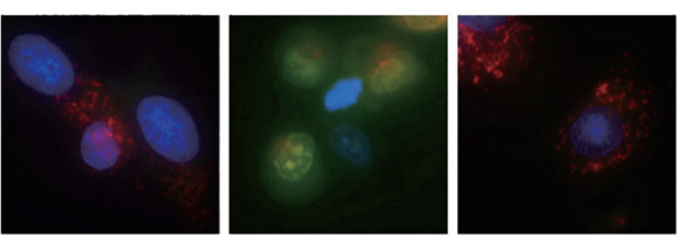

$E$

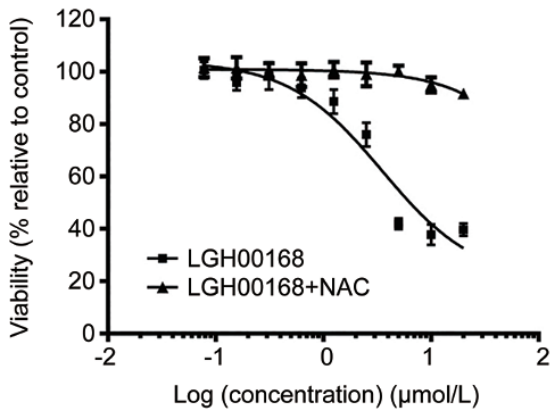

tive responses in the host ${ }^{[50]}$. Moreover, most chemotherapy drugs induce apoptosis, but some drugs can cause necro$\operatorname{sis}^{[51,52]}$. Additionally, drug resistance is often associated with an imbalance in pro-apoptotic and anti-apoptotic mediators, with the net result favoring cell survival. Here, we identified LGH00168 as a new necroptosis inducer. We propose that LGH00168 stimulates severe ER stress, NF-kB inhibition, ROS production, MMP loss and severe LMP induction, which finally lead to necroptosis in A549 cells. LGH00168, which shows good anti-cancer activity in vitro and in vivo, has potential as a new drug candidate and provides an ideal strategy for developing combination therapies to eliminate subpopulations of cells that are resistant to apoptotic cell death. Additionally, the further study of LGH00168 would provide more detailed information about its anti-cancer mechanism, which might be helpful for further optimization.

\section{Abbreviations}

CHOP, C/EBP homologous protein; GADD153, growth arrestand DNA damage-inducible gene 153; HTS, high-throughput
B
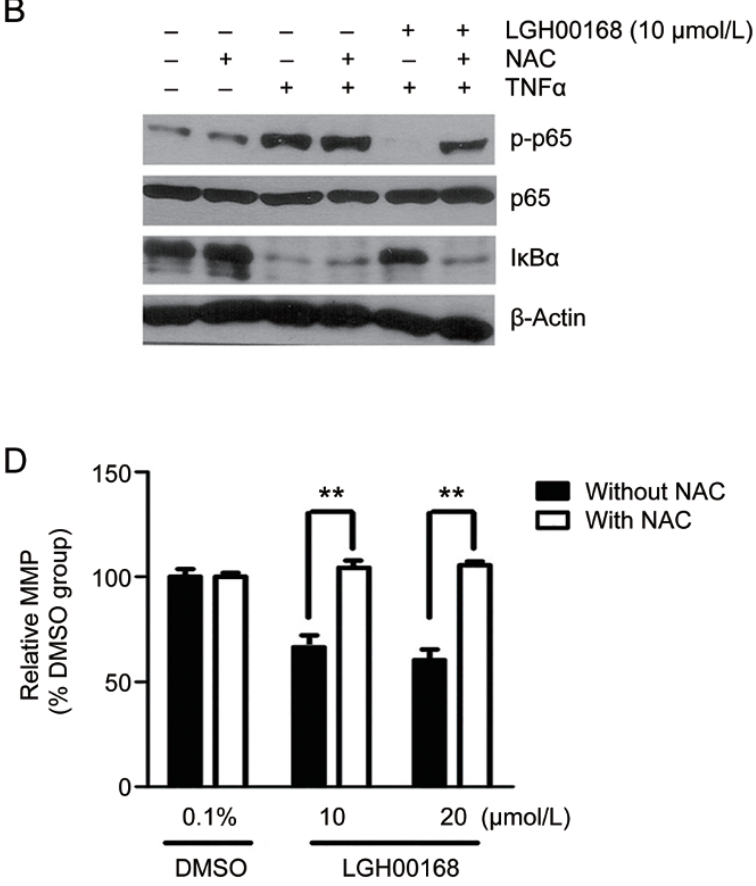

Figure 5. The ROS scavenger NAC (10 mmol/L) blocked LGH00168-induced CHOP activation, NF-KB inhibition, and necroptosis in A549 cells. (A) NAC reversed LGH00168-induced CHOP activation. (B) NAC reversed LGH00168-induced NF-KB inhibition. (C) NAC blocked LGH00168-induced LMP. (D) NAC blocked LGH00168-induced MMP collapse. (E) NAC protected cells from LGH00168-induced necroptotic cell death. ${ }^{* *} P<0.01$. 
screening; MTT, methylthiazolyldiphenyl-tetrazolium bromide; $\mathrm{CT}$, cycle threshold; ER, endoplasmic reticulum; $\mathrm{UPR}$, unfolded protein response; $\mathrm{XBP1}$, $\mathrm{X}$-box binding protein 1; DISC, death-inducing signaling complex; NF-kB, nuclear factor $\mathrm{\kappa B}$; NSCLC, non-small cell lung cancer; PMP, plasma membrane permeabilization; LMP, lysosomal membrane permeabilization; MMP, mitochondrial membrane potential; $\mathrm{AO}$, acridine orange; $\mathrm{HO}$, Hoechst 33342; qPCR, quantitative polymerase chain reaction; RIP1, receptor-interacting protein $1 ; \triangle \psi \mathrm{M}$, mitochondrial membrane potential; mitoROS, mitochondrial ROS; NAC, N-Acetyl-L-Cysteine; SRB, sulforhodamine B; Nec-1, necrostatin-1.

\section{Acknowledgements}

This work was supported by grants from the National Natural Science Foundation of China (№ 81072667, 81473244, and 91029716) and the State Key Laboratory of Natural and Biomimetic Drugs (K20130202).

\section{Author contribution}

Yi-ming MA, Yan-min PENG, Qiong-hua ZHU, An-hui GAO, Bo CHAO, Qiao-jun HE, You-hong HU, Jia LI, and Yu-bo ZHOU conceived and designed the experiments; Yi-ming MA, Yan-min PENG, Qiong-hua ZHU, and An-hui GAO performed the experiments; Yi-ming MA, Yan-min PENG, Qionghua ZHU, and An-hui GAO analyzed the data; Yi-ming MA and Yu-bo ZHOU wrote the paper.

\section{References}

1 Stewart BW, Wild PC. World Cancer Report 2014. p 632.

2 Wang FW, Wang SQ, Zhao BX, Miao JY. Discovery of 2'-hydroxychalcones as autophagy inducer in A549 lung cancer cells. Org Biomol Chem 2014; 12: 3062-70.

3 Keith RL, Miller YE. Lung cancer chemoprevention: current status and future prospects. Nat Rev Clin Oncol 2013; 10: 334-43.

4 Pirker R. Novel drugs against non-small-cell lung cancer. Curr Opin Oncol 2014; 26: 145-51.

5 Goffin J, Lacchetti C, Ellis PM, Ung YC, Evans WK. First-line systemic chemotherapy in the treatment of advanced non-small cell lung cancer: a systematic review. J Thorac Oncol 2010; 5: 260-74.

6 Minguet J, Smith KH, Bramlage P. Targeted therapies for treatment of non-small cell lung cancer - recent advances and future perspectives. Int J Cancer 2016; 138: 2549-61.

7 Malhotra JD, Kaufman RJ. Endoplasmic reticulum stress and oxidative stress: a vicious cycle or a double-edged sword? Antioxid Redox Signal 2007; 9: 2277-93.

8 Saveljeva S, Mc Laughlin SL, Vandenabeele P, Samali A, Bertrand MJ. Endoplasmic reticulum stress induces ligand-independent TNFR1mediated necroptosis in L929 cells. Cell Death Dis 2015; 6: e1587.

9 Kitsis RN, Molkentin JD. Apoptotic cell death "Nixed" by an ERmitochondrial necrotic pathway. Proc Natl Acad Sci U S A 2010; 107: 9031-2.

10 Janssen K, Horn S, Niemann MT, Daniel PT, Schulze-Osthoff K, Fischer U. Inhibition of the $\mathrm{ER} \mathrm{Ca}{ }^{2+}$ pump forces multidrug-resistant cells deficient in Bak and Bax into necrosis. J Cell Sci 2009; 122: 448191.

11 Logue SE, Cleary P, Saveljeva S, Samali A. New directions in ER stress-induced cell death. Apoptosis 2013; 18: 537-46.
12 van Schadewijk A, van't Wout EF, Stolk J, Hiemstra PS. A quantitative method for detection of spliced X-box binding protein-1 (XBP1) mRNA as a measure of endoplasmic reticulum (ER) stress. Cell Stress Chaperones 2012; 17: 275-9.

13 Lee AS. The ER chaperone and signaling regulator GRP78/BiP as a monitor of endoplasmic reticulum stress. Methods 2005; 35: 37381.

14 Yang J, Zong YN, Zhou L, Liu QL. Close and allosteric opening of the polypeptide-binding site in a human Hsp70 chaperone BiP. Structure 2015; 23: 2191-203.

15 Dalton LE, Clarke HJ, Knight J, Lawson MH, Wason J, Lomas DA, et al. The endoplasmic reticulum stress marker $\mathrm{CHOP}$ predicts survival in malignant mesothelioma. Br J Cancer 2013; 108: 1340-7.

16 Nishitoh $\mathrm{H}$. CHOP is a multifunctional transcription factor in the ER stress response. J Biochem 2012; 151: 217-9.

17 Kim I, Xu W, Reed JC. Cell death and endoplasmic reticulum stress: disease relevance and therapeutic opportunities. Nat Rev Drug Discov 2008; 7: 1013-30.

18 Oyadomari S, Mori M. Roles of CHOP/GADD153 in endoplasmic reticulum stress. Cell Death Differ 2004; 11: 381-9.

19 Yamaguchi H, Wang HG. CHOP is involved in endoplasmic reticulum stress-induced apoptosis by enhancing DR5 expression in human carcinoma cells. J Biol Chem 2004; 279: 45495-502.

20 Degterev A, Yuan J. Expansion and evolution of cell death programmes. Nat Rev Mol Cell Biol 2008; 9: 378-90.

21 Hengartner MO. The biochemistry of apoptosis. Nature 2000; 407: 770-6.

22 Majno G, Joris I. Apoptosis, oncosis, and necrosis. An overview of cell death. Am J Pathol 1995; 146: 3-15.

23 Christofferson DE, Yuan J. Necroptosis as an alternative form of programmed cell death. Curr Opin Cell Biol 2010; 22: 263-8.

24 Thapa RJ, Nogusa S, Chen P, Maki JL, Lerro A, Andrake M, et al. Interferon-induced RIP1/RIP3-mediated necrosis requires PKR and is licensed by FADD and caspases. Proc Natl Acad Sci U S A 2013; 110: E3109-18.

25 Guicciardi ME, Gores GJ. Life and death by death receptors. FASEB J 2009; 23: 1625-37.

26 Walczak H. Death receptor-ligand systems in cancer, cell death, and inflammation. Cold Spring Harb Perspect Biol 2013; 5: a008698.

27 Giampietri C, Starace D, Petrungaro S, Filippini A, Ziparo E. Necroptosis: molecular signalling and translational implications. Int J Cell Biol 2014; 2014: 490275.

28 Marshall KD, Baines CP. Necroptosis: is there a role for mitochondria? Front Physiol 2014; 5: 323.

29 Dillon CP, Weinlich R, Rodriguez DA, Cripps JG, Quarato G, Gurung P, et al. RIPK1 blocks early postnatal lethality mediated by caspase-8 and RIPK3. Cell 2014; 157: 1189-202.

30 Green DR, Oberst A, Dillon CP, Weinlich R, Salvesen GS. RIPKdependent necrosis and its regulation by caspases: a mystery in five acts. Mol Cell 2011; 44: 9-16.

31 Degterev A, Hitomi J, Germscheid M, Chen IL, Korkina O, Teng X, et al. Identification of RIP1 kinase as a specific cellular target of necrostatins. Nat Chem Biol 2008; 4: 313-21.

32 Lin Y, Choksi S, Shen HM, Yang QF, Hur GM, Kim YS, et al. Tumor necrosis factor-induced nonapoptotic cell death requires receptorinteracting protein-mediated cellular reactive oxygen species accumulation. J Biol Chem 2004; 279: 10822-8.

33 Degterev A, Huang Z, Boyce M, Li Y, Jagtap P, Mizushima N, et al. Chemical inhibitor of nonapoptotic cell death with therapeutic potential for ischemic brain injury. Nat Chem Biol 2005; 1: 112-9.

34 Jaramillo ML, Banville M, Collins C, Paul-Roc B, Bourget L, O'Connor- 
McCourt M. Differential sensitivity of A549 non-small lung carcinoma cell responses to epidermal growth factor receptor pathway inhibitors. Cancer Biol Ther 2008; 7: 557-68.

35 Zang Y, Yu LF, Pang T, Fang LP, Feng X, Wen TQ, et al. AICAR induces astroglial differentiation of neural stem cells via activating the JAK/ STAT3 pathway independently of AMP-activated protein kinase. J Biol Chem 2008; 283: 6201-8.

36 McKeague AL, Wilson DJ, Nelson J. Staurosporine-induced apoptosis and hydrogen peroxide-induced necrosis in two human breast cell lines. Br J Cancer 2003; 88: 125-31.

37 Mpoke SS, Wolfe J. Differential staining of apoptotic nuclei in living cells: application to macronuclear elimination in Tetrahymena. J Histochem Cytochem 1997; 45: 675-83.

38 Qiu BY, Turner N, Li YY, Gu M, Huang MW, Wu F, et al. High-throughput assay for modulators of mitochondrial membrane potential identifies a novel compound with beneficial effects on $d b / d b$ mice. Diabetes 2010; 59: 256-65.

39 Dive C, Gregory CD, Phipps DJ, Evans DL, Milner AE, Wyllie AH. Analysis and discrimination of necrosis and apoptosis (programmed cell death) by multiparameter flow cytometry. Biochim Biophys Acta 1992; 1133: 275-85.

40 Kondo Y, Kanzawa T, Sawaya R, Kondo S. The role of autophagy in cancer development and response to therapy. Nat Rev Cancer 2005; 5: 726-34.

41 Janku F, McConkey DJ, Hong DS, Kurzrock R. Autophagy as a target for anticancer therapy. Nat Rev Clin Oncol 2011; 8: 528-39.

42 Mansilla S, Bataller M, Portugal J. Mitotic catastrophe as a consequence of chemotherapy. Anticancer Agents Med Chem 2006; 6: 589-602.
43 Amaravadi RK, Thompson CB. The roles of therapy-induced autophagy and necrosis in cancer treatment. Clin Cancer Res 2007; 13: 7271-9.

44 Caffrey PB, Frenkel GD. Selenite cytotoxicity in drug resistant and nonresistant human ovarian tumor cells. Cancer Res 1992; 52: 4812-6.

45 Shilo S, Tirosh 0 . Selenite activates caspase-independent necrotic cell death in Jurkat T cells and J774.2 macrophages by affecting mitochondrial oxidant generation. Antioxid Redox Signal 2003; 5: 273-9.

46 Duanmu J, Cheng J, Xu J, Booth CJ, Hu Z. Effective treatment of chemoresistant breast cancer in vitro and in vivo by a factor VIItargeted photodynamic therapy. Br J Cancer 2011; 104: 1401-9.

47 Festjens N, Vanden Berghe T, Vandenabeele P. Necrosis, a wellorchestrated form of cell demise: signalling cascades, important mediators and concomitant immune response. Biochim Biophys Acta 2006; 1757: 1371-87.

48 Henriquez M, Armisen R, Stutzin A, Quest AF. Cell death by necrosis, a regulated way to go. Curr Mol Med 2008; 8: 187-206.

49 Murphy MP. How mitochondria produce reactive oxygen species. Biochem J 2009; 417: 1-13.

50 Zong WX, Thompson CB. Necrotic death as a cell fate. Genes Dev 2006; 20: 1-15.

51 Li L, Han W, Gu Y, Qiu S, Lu Q, Jin J, et al. Honokiol induces a necrotic cell death through the mitochondrial permeability transition pore. Cancer Res 2007; 67: 4894-903.

52 Miyoshi N, Watanabe E, Osawa T, Okuhira M, Murata Y, Ohshima H, et al. ATP depletion alters the mode of cell death induced by benzyl isothiocyanate. Biochim Biophys Acta 2008; 1782: 566-73. 